\title{
PKM USAHA PENGOLAHAN KERIPIK SANJAI BALADO DALAM MENGHADAPI MASALAH PRODUKTIVITAS DI KECAMATAN MEDAN AMPLAS KOTA MEDAN PROVINSI SUMATERA UTARA
}

\author{
Bobby Umroh' ${ }^{1)}$, Darianto ${ }^{2)}$, Kamaluddin ${ }^{3)}$ \\ Universitas Medan Area ${ }^{1)}$ \\ Universitas Medan Area ${ }^{2)}$ \\ Universitas Medan Area ${ }^{3)}$
}

\begin{abstract}
ABSTRAK
Usaha yang dilakukan oleh Bapak Mahdian adalah industri rumah tangga (Home Industry) yang berada di J1. Panglima Denai Gg.Hasibuan No.10 Kecamatan Medan Amplas. Usaha ini memiliki potensi yang luar biasa karena produk ini berupa Keripik Sanjai Balado yang berasal dari ubi roti melalui proses pengolahan yang sederhana. Selain itu pangsa pasar produk ini sangat luas sebab pengusaha produksi mengalami kewalahan dalam memenuhi permintaan. Jenis usaha yang dilakukan adalah produksi pengolahan ubi kayu menjadi Keripik Sanjai Balado yang dapat digunakan sebagai oleh-oleh dari Kota Medan. Masalah yang dihadapi mitra adalah proses pengolahan masih menggunakan cara-cara tradisional, terutama pada proses pencampuran bumbu dengan keripik ubi, yaitu dengan cara memasukkan bahan ke dalam baskom dengan cara menggoyang-goyangkannya. Kapasitas produksi saat ini sebanyak $\pm 100 \mathrm{~kg} / \mathrm{hari}$ atau sama dengan $130 \mathrm{~kg}$ ubi kayu selama 8 jam kerja/hari. Oleh karena itu, diperlukan sebuah rancangan mesin pencampur keripik ubi dengan bumbu dan mesin penggiling bumbu dengan metode penerapan teknologi tepat guna yang mampu bekerja lebih cepat, efisien, dan higienis dengan indikator peningkatan kapasitas produksi di atas $150 \mathrm{~kg} / \mathrm{hari}$ Keripik Sanjai Balado selama 8 jam kerja/hari agar masyarakat terbantu secara ekonomi. Dari pengabdian yang dilakukan diperoleh peningkatan produksi dalam waktu 5 jam sebesar $160 \mathrm{Kg}$ /hari dengan peningkatan $200 \%$ dari sistem manual.
\end{abstract}

Kata kunci: Usaha keripik sanjai balado, mesin pencampur keripik ubi dengan bumbu, mesin penggiling bumbu, peningkatan produktivitas

\begin{abstract}
The business carried out by Mr. Mahdian is a home industry located on Jl. Panglima Denai Gg. Hasibuan No.10 Medan Amplas District. This business has tremendous potential because this product is in the form of Sanjai Balado Chips from sweet potato bread through a simple processing. In addition, the market share of this product is very broad because production entrepreneurs are overwhelmed in meeting demand. The type of business carried out is the production of processing cassava into Sanjai Balado Chips which can be used as souvenirs from Medan City. The problem faced by partners is that the processing process still uses traditional methods, especially in the process of mixing herbs with sweet potato chips, which is by putting ingredients into the basin by shaking them. The current production capacity is $\pm 100 \mathrm{~kg} / \mathrm{day}$ or equal to $130 \mathrm{~kg}$ of cassava for 8 working hours / day. Therefore, it is necessary to design a machine to mix sweet potato chips with spices and seasoning grinder with appropriate technology application methods that are able to work faster, more efficiently, and hygienically with an indicator of increasing production capacity above $150 \mathrm{~kg} /$ day Sanjai Balado Chips for 8 hours work / day so that the community is helped economically. From the dedication, an increase in production within 5 hours of $160 \mathrm{~kg} /$ day increased $200 \%$ from a manual system
\end{abstract}

Keywords: Sanjai Balado chips business, sweet potato chips and spices mixing machine, seasoning grinder, productivity improvement.

\section{PENDAHULUAN}

Mitra yang akan di tuju pada pengabdian ini adalah seorang pengrajin/pengusaha yang memiliki 4 orang karyawan dengan cara memanfaatkan ubi kayu yang melimpah ruah di daerah sumatera utara untuk dijadikan menjadi usaha 
rumahan yaitu pengolahan Keripik Sanjai Balado dalam bentuk kemasan penganan camilan sebagai oleh-oleh dari Kota Medan. Pada awalnya usaha ini memproduksi sekitar $\pm 50 \mathrm{~kg} / \mathrm{hari}$ ubi kayu mentah, setelah beberapa tahun meningkat menjadi \pm 150 $\mathrm{kg} /$ hari dengan hasil $\pm 100 \mathrm{~kg} / \mathrm{hari}$ Keripik Sanjai Balado. Dalam sehari Bapak Mahdian mampu mencampur keripik ubi dengan bumbunya sebanyak $\pm 100 \quad \mathrm{~kg}$. Namun belakangan ini permintaan pasar terus meningkat yaitu lebih dari 200 $\mathrm{kg} /$ hari, karena pemasarannya telah menyebar melalui gerai-gerai penjualan Careefour, Indomart \& Alfamart, akan tetapi permintaan ini selalu tidak dapat dipenuhi karena rumitnya sistem pencampuran bumbu basah jika menggunakan tangan/manual. Jika di maka hasil yang dicampur bisa tidak jadi merata. Beberapa penelitian memaparkan bahwa Perkembangan ilmu pengetahuan dan teknologi (IPTEK) mendorong manusia untuk berpikir menciptakan suatu peralatan yang lebih efisien dan praktis serta dapat membantu bahkan menggantikan tenaga manusia (M.Y.Fanni et antara lain, 2012). Mekanisme pertanian adalah bagian penting dari industri pertanian saat ini yang berujung pada sistem mekanisasi proses produk pertanian (A.R Tanjung et al, 2015). Teknologi tepat guna dalam bidang pengolahan bahan baku semakin pesat berkembang, dalam hal ini peran IPTEK telah membuktikan bahwa sangat berpotensi di dalam meningkatkan produktifitas hasil industri. Oleh karena itu kolaborasi antara pengolahan bahan baku dengan hasil industri memerlukan ketepatan waktu untuk menunjukkan kinerja yang baik. Untuk itu industri diharuskan menggunakan teknologi tepat guna dengan tenaga mekanis di dalam sistem pengolahan bahan baku ubi kayu yang diproduksi menjadi Keripik Sanjai Balado dalam bentuk kemasan penganan cemilan sehingga produktifitas dapat dicapai semaksimal mungkin. Pada dasarnya permasalahan yang dihadapi MITRA sangat berkaitan dengan proses produksi yang sangat konvensional dan belum disentuh oleh teknologi tepat guna dengan mekanisasi mesin pencampur keripik ubi dengan bumbu dan mesin penggiling bumbu. Saat ini, proses konvensional pencampuran keripik ubi dengan bumbu dan penggilingan bumbu dilakukan secara manual, membuat tangan bagian atas pegal sangat rentan terhadap tingkat kelelahan pekerja jika terus menerus bekerja selama lebih kurang 2 jam dan hasil yang dapat diproduksi tidak maksimal. Selain itu permasalahan yang lain adalah sirkulasi udara belum memenuhi standard usaha karena ruangan tertutup.

\section{METODE PELAKSANAAN}

Adapun metode yang kami lakukan kepada pengusaha keripik terdiri dari 2 tahap yaitu tahap identifikasi masalah dan mengatasi masalah mitra, oleh karena itu tahapan yang kami lakukan harus berdasarkan permasalahan yang dialami langsung oleh Mitra;

2.1 Identifikasi Masalah, pada point ini kami melakukan proses identifikasi sebagai berikut

1. Berkunjung ke lokasi Pengabdian Masyarakat Teknik Mesin UMA pada Program Kemitraan Masyarakat yang berjumlah 3 orang berkunjung ke Pabrik Keripik Sanjai Balado di Jl. Panglima Denai Gg.Hasibuan 
No.10 Kecamatan Medan Amplas.

2. Kami dari Tim PKM memperkenalkan diri dan menanyakan tentang permasalahan yang dihadapi oleh pengusaha keripik sanjai balado yang kami sebut sebagai MITRA Ternyata permasalahan yang dihadapi adalah Kebutuhan mereka terhadap mekanisasi mesin pencampur keripik ubi dan area masak tempat penggorengan tidak memiliki sirkulasi yang baik.

3. Mempelajari Proses pencampuran bumbu dengan waktu yang digunakan sehingga menjadi hasil produk yang layak untuk dijual dengan kualitas yang baik.

4. Memperhatikan tempat yang layak untuk menggoreng pada area masak kripik ubi, dari hasil identifikasi terlihat bahwa tempat penggorengan tidak memiliki sirkulasi udara yang baik sehingga operator yang memasak dapat terganggu kesehatannya.

\subsection{Mengatasi masalah dengan Penerapan Teknologi Tepat Guna}

Adapun langkah Penerapan Teknologi Tepat Guna (PTTG) dimulai dengan beberapa tahapan diantaranya adalah :

1. Desain dan rancang alat dengan spesifikasi sebagai berikut

Daya : 0,5 HP

Dimensi : 98 × 70 x $60 \mathrm{~cm}$

Putaran motor : $1400 \mathrm{rpm}$

Putaran Wadah : $40 \mathrm{rpm}$

Kapasitas : 50 kg/jam

Dari hasil perancangan diperoleh desain berupa gambar autocad dengan dimensi yang sesuai dengan model yang diharapkan mitra terlihat pada gambar 1 , model pencampuran dirancang dengan sistem bolak balik agar pencampuran merata menggunakan daya 1 phase.

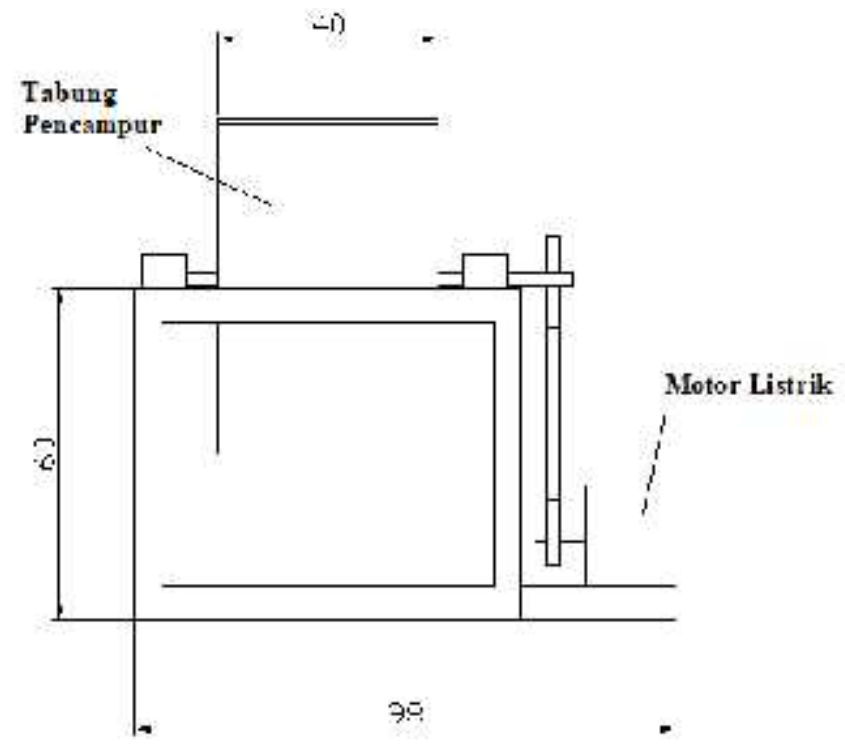

Gambar 1. Desain mesin pencampur bumbu balado 
2. Melakukan Proses produksi dan perakitan mesin pencampur bumbu

3. Memasang Exhause Fan pada area masak dan mengarahkannya ke fentilasi udara.

\section{HASIL DAN PEMBAHASAN}

Pembahasan yang dilakukan merupakan pembahasan dari hasil yang didapat selama melakukan program. Mulai dari analisis situasi, mempelajari proses, uji coba alat, pengenalan alat dan penerapan ilmu pengetahuan dan teknologi.

\subsection{Uji sistem mekanisasi alat}

Pengujian mekanik yang dilakukan meliputi bagian poros saat memutar wadah pencampur dengan berisikan kerupuk yang telah bercampur dengan bumbu, kekuatan poros, kekuatan puli, kekuatan belting, kekuatan bearing, kekakuan tempat wadah dan kemampuan daya penggerak. Hasil uji sistem mekanik dipaparkan pada tabel 1 sebagai berikut :

Tabel 1. Hasil Pengujian Sistem Mekanik

\begin{tabular}{lll}
\hline No & Pengujian & Hasil \\
\hline 1 & Pengujian Poros & Poros penahan beban akibat beban puntir
\end{tabular}

2 Pengujian Puli tidak mengalami masalah.

\section{Pengujian Puli}

3 Pengujian Belting

$4 \quad$ Kekuatan Bearing

5 Tempat Wadah

$6 \quad$ Motor listrik

\subsection{Pengujian Hubungan Waktu Terhadap Massa Kripik Ubi}

Pengujian ini dilaksanakan denagn tujuan untuk mengetahui kecepatan
Puli yang dipasang menggunakan bahan steel sehingga mampu menahan putaran tinggi ataupun rendah

Tali belting yang digunakan menggunakan tye A cocok untuk beban yang keci sehingga tetap kondisi aman

Bearing jenis type UCF 1" dan 3/4 “ berada dalam kondisi aman.

Dudukan wadah yang digunakan cocok untuk ukuran tampungan $2-5 \mathrm{~kg}$ terbuat dari steel sehingga tetap dalam kondisi aman.

Daya yang digunakan pada alat ini sebesar 450 watt dengan putaran bolak balik waktu antara pencampuran secara manual dengan waktu menggunakan alat/mesin sebagai mana tabel 2 berikut :

Tabel 2. Data waktu pencampuran terhadap jumlah massa keripik ubi

\begin{tabular}{lll}
\hline $\begin{array}{l}\text { waktu } \\
\text { (menit) }\end{array}$ & Jumlah Massa kripik $(\mathrm{Kg})$ & \\
\cline { 2 - 3 } & Manual & Mesin \\
\hline 15 & 3,00 & 9,00 \\
45 & 6,00 & 18,00 \\
\hline
\end{tabular}


Dari Tabel 2 diperoleh bahwa rata-rata jumlah massa keripik 12 $\mathrm{Kg} / \mathrm{jam}$ jika dikerjakan dalam waktu 5 jam maka diperoleh total massa 60 $\mathrm{Kg} / \mathrm{Hari}$. Sedangkan menggunakan mesin $36 \mathrm{Kg} / \mathrm{jam}$ total yang diperoleh dalam waktu 1 hari $180 \mathrm{Kg}$ dalam hal ini ada peningkatan 200\%. Dengan demikian penerapan Ipteks mampu memangkas waktu produksi dan meningkatkan kapasitas sehingga telah mampu memenuhi peluang pasar.

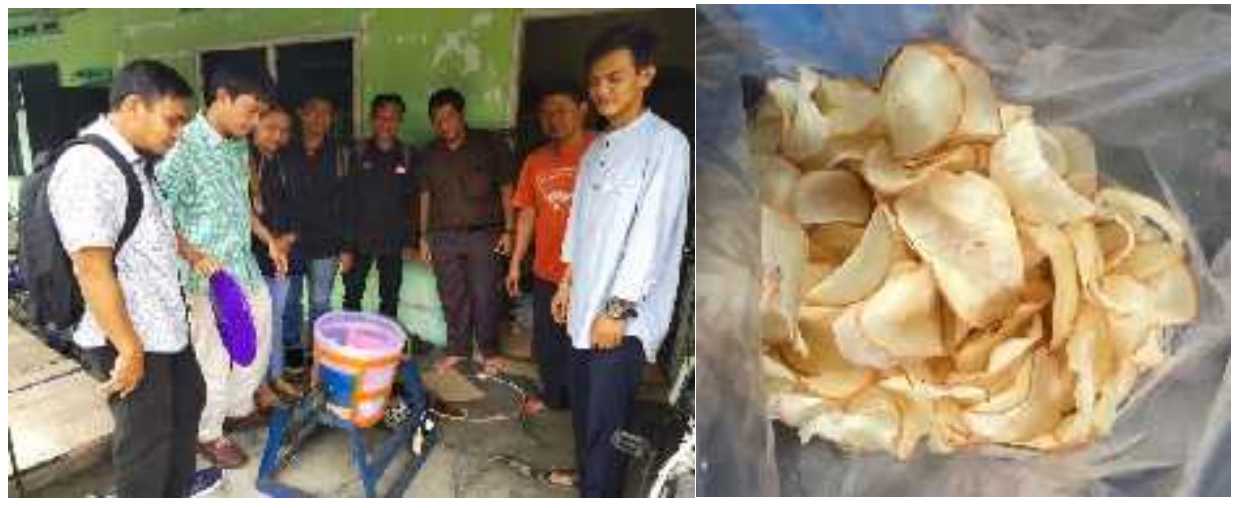

Gambar 2. Pengujian Mesin PencampurBumbu

\subsection{Pengujian pencampuran terhadap daya yang digunakan \\ Pengujian ini dilaksanakan} untuk mengetahui hubungan antara waktu yang di butuhkan, massa kripik ubi dan daya yang dipakai selama waktu proses pencampuran bumbu pada kripik dengan beberapa pembebanan.

Tabel 2. Proses pencampuran dalam waktu

\begin{tabular}{lccc}
\hline No & Waktu (Menit) & Jumlah Massa $(\mathrm{Kg})$ & Daya (watt) \\
\hline 1 & 15 & 9,00 & 150 \\
2 & 30 & 18,00 & 250 \\
3 & 45 & 27,00 & 350 \\
\hline
\end{tabular}

Dari hasil pengujian tersebut diketahui bahwa rata-rata waktu pencampuran menjadi merata dan dapat diproses dengan mengganti tempat / wadah dari pencampurannya beberapa kali sampai dengan 45 menit dengan massa kripik $27 \mathrm{Kg}$ dan daya dipakai 350 watt.

Dari awal analisis situasi yang dilakukan bahwa permasalahan utama adalah rumitnya mencari tenaga kerja menggunakan cara manual sampai pada akhirnya produktivitas yang diperoleh tidak mencapai target produksi. Oleh karena itu, pada saat pencampuran menggunakan mesin, selain dari pada pengujian daya yang dipakai juga dilakukan pengujian terhadap dampak pembebanan yang diberikan. Dari pengujian yang dilakukan pada saat mencampur bumbu, diketahui mesin tidak mengalami slip pada belting dan off pada motor, artinya daya dan mekanisasi pada mesin sudah berjalan dengan baik. 


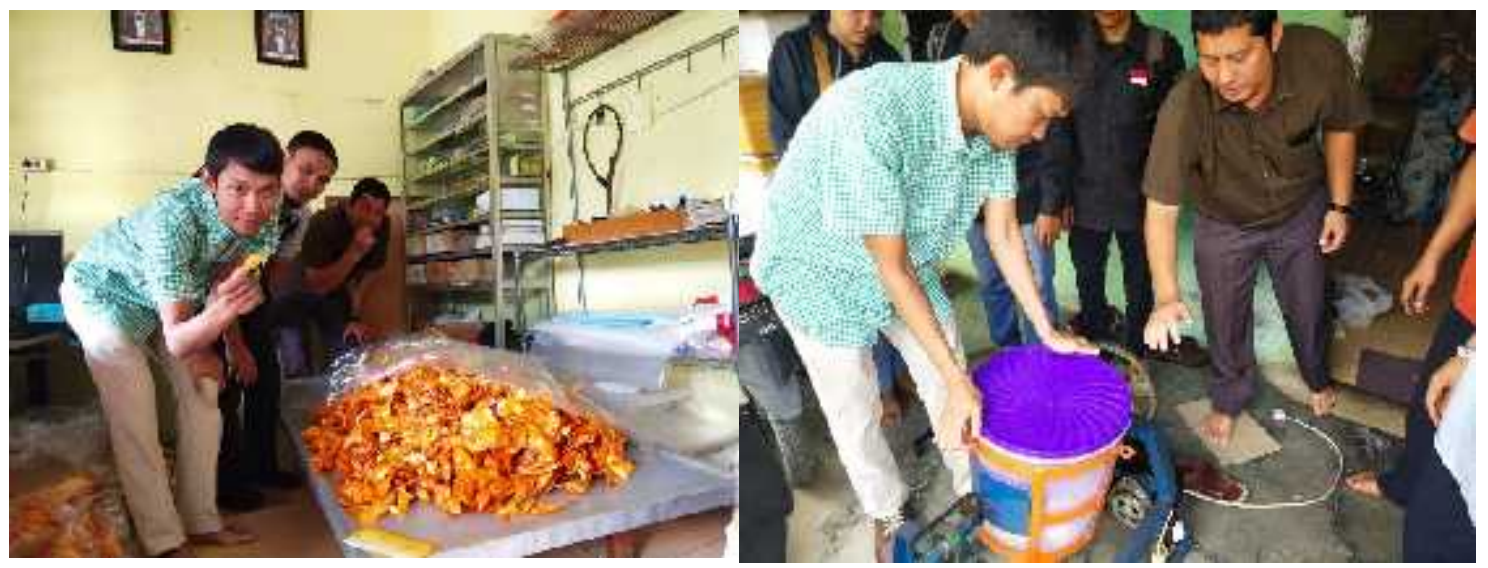

Gambar 3. Lanjutan pengujian waktu terhadap kualitas

\subsection{Penerapan Iptek Terhadap Kenyamanan Kerja dan Analisis Produktivitas}

Dari analisis situasi sebelum penerapan ipteks diketahui bahwa pengusaha sulit mencari tenaga kerja dikarenakan manusia selalu mengalami kelelahan dalam mencampur bumbu, selain itu juga jika menggunakan tenaga manusia ada kalanya kehigienisan yang diperoleh tidak dapat terjamin. Oleh karena itu kondisi ini sudah dapat teratasi dimana operator hanya cukup menyiapkan beberapa tempat/wadah yang sudah berisikan kripik dan bumbunya lalu menenkan tombol on/off saja. Hal ini bisa dilkaukan beberapa kali sebagaimana pengujian yang sudah dilakukan. Masalah kehigienisan juga sudah dapat diatasi dikarenakan tenaga manusia yang digunakan tidak terlalu kuat.

Selain dari pada proses pencampuran tim PKM UMA dari Prodi Teknik Mesin Fakultas Teknik juga melakukan penyuluhan terhadap area penggorengan, dari analisis situasi yang kami lakukan bahwa ruangan penggorengan yang hanya
$2 \times 3 \mathrm{~m}$ ini tidak memiliki sirkulasi yang baik sehingga dalam analisa sederhana kami bahwa ruangan tersebut kurang sehat akibat dari asap penggorengan sehingga kami memasang Exhause Fan sebagai penghisap udara dari ruangan tersebut dan mengarahkan asap sisa keluar ruangan. Dari pernyataan pekerja bahwa mereka lebih merasakan kenyamanan dan tidak lagi mengalami batu ataupun mata berair pada saat menggoreng keripik ubi diruangan $2 \times 3 \mathrm{~m}$ tersebut. Oleh karena itu dampak ipteks yang dilakukan bukan hanya meningkatkan produktifitas akan tetapi juga memberikan kenyamanan dan kesehatan bagi pekerja yang mencari nafkah pada usaha ini. 


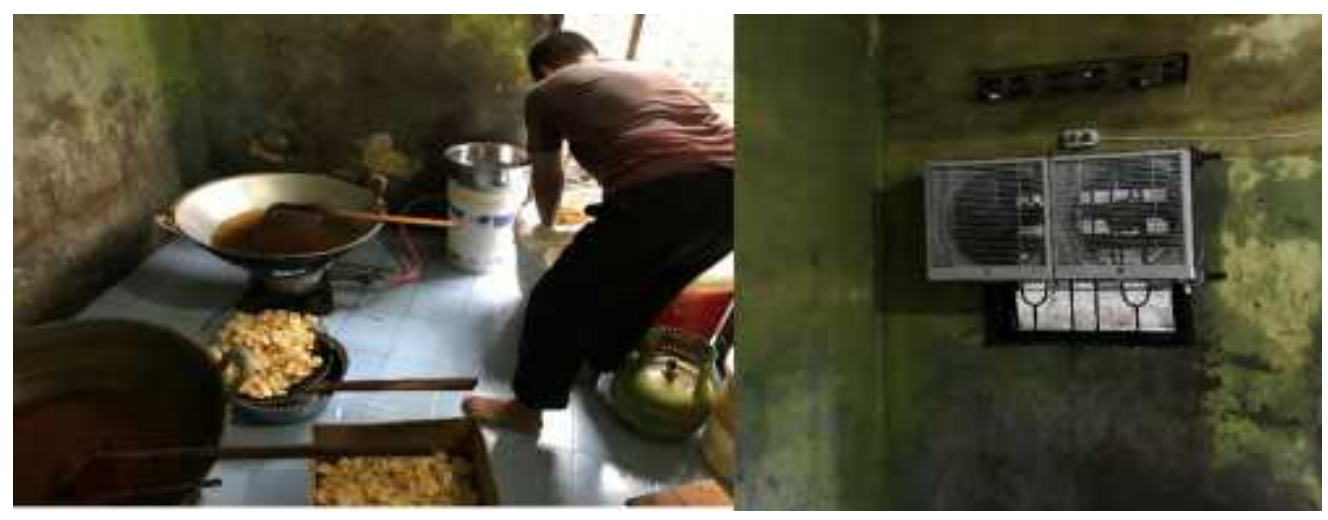

Gambar 4. Area Dapur Pengorengan Keripik Ubi

\section{Kesimpulan}

1. Kegiatan yang dilakukan merupakan salah satu kegiatan penerapan ipteks dalam hal ini teknologi tepat guna dan penyuuluhan, yaitu dengan merubah dari sistem yang manual menjadi pencampur dengan sistem mekanis sehingga terjadi peningkatan produksi pada usaha kripik ubi serta kenyamanan pada tempat bekerja di sistem penggorengan.

2. Terjadi peningkatan produktivitas yang di buktikan dengan beberapa pengujian dari kapasitas produksi 60 $\mathrm{Kg} /$ hari menjadi $180 \mathrm{Kg} / \mathrm{hari}$ dengan presentase naik 200 $\%$.

3. Kapasitas produksi yang dihasilkan adalah $180 \mathrm{~kg} / \mathrm{hari}$ telah cukup untuk memenuhi permintaan pasar diatas 150 $\mathrm{Kg} / \mathrm{hari}$.

4. Alat yang dirancang dapat dipakai pada daya listrik yang kecil sehingga memudahkan untuk penggunaan home industri.

5. Sulitnya mencari tenaga kerja untuk mencampur bumbu sudah dapat teratasi dengan kualitas yang lebih merata dan lebih baik.

\section{REFERENSI}

Y. Akmal. 2016. Analisis Faktorfaktor Yang Mempengaruhi Produktivitas Tenaga Kerja Produksi Kecil Kerupuk Sanjai di Kota Bukittinggi.

T. Muhandri, O. Rezki. 2016. Perbaikan Mutu dan Penyusunan Instruksi Kerja pada Pembuatan Keripik Sanjai Balado Nina di Bukittinggi. Jurnal Ilmiah Pengabdian kepada Masyarakat. jurnal.ipb.ac.id

N.Nurwati, R.Nizar, A.Amalia. 2017. Analisis Agroindustri Keripik Ubi Kayu di Kelurahan Kulim Kecamatan Tenayan Raya Kota Pekanbaru. Jurnal Ilmiah Pertanian. Vol 14 No.1, Agustus 2017. ejurnal.unilak.ac.id

Fedia Restu, 2013. Rekayasa Mesin Pemilah dan Penghancur Sampah Otomatis Dengan Sistem Kendali Kontrol Sederhana Pada Skala Internal Politeknik Negeri Batam. 
Jurnal politeknik Negeri Batam.

M.Muzakki. 2012. Optimalisasi Keuntungan pada Perusahaan Keripik Balado Mahkota dengan Metode Simpleks. Jurnal Matematika UNAND. Jmua.fmipa.unand.ac.id

Peniel I.Gultom, Priscilla Tamara, Erni J. Sinaga, Mujiono. 2017. Penerapan Alat Pencampur bumbu di Sentra Industri Kecil Keripik Tempe Sanan. Jurnal Flywheel, Vol. 8, Nomor 1.

Sudjatinah Sudjatinah, Cornelius Hari Wibowo, Iswoyo Iswoyo.. 2017. IBM Pengrajin Abon dan Dendeng Sapi. Jurnal Dinamika Sosial Budaya. P.ISSN 1410-9859. journals.usm.ac.id 